\title{
SCIDAC - CENTER FOR PLASMA EDGE SIMULATION - GENERAL ATOMICS SUPPORT OF NYU COLLABORATION
}

Final Report

\author{
by \\ F.L. HINTON and PROJECT STAFF
}

Prepared under

Contract No. DE-FC02-06ER54847

for DOE Office of Science, Chicago

GENERAL ATOMICS PROJECT 30269

DATE PUBLISHED: JUNE 2009 


\title{
SciDAC - Center for Plasma Edge Simulation - General Atomics Support of NYU Collaboration - Final Report
}

Report for contract period 4/27/06 - 1/15/07

\author{
Fred L. Hinton \\ Hinton Associates, Escondido, CA
}

\begin{abstract}
Methods for implementing Coulomb collisions in particle codes were studied and developed. At first, a lattice-Boltzmann method seemed promising. After considering this in more detail, it was found not to be efficient enough. A method was then sought for implementing collisional effects as changes in particle weights, instead of changes in velocities. Although this may eventually be done, it was decided that a Langevin method would be more straightforward to develop, since it was possible to build on previous work. The rest of the contract period was spent developing the Langevin method, which ultimately resulted in a published paper, in April 2008 [F.L. Hinton, Phys. Plasma 15, 042501 (2008)].
\end{abstract}


GENERAL ATOMICS

P.O. BOX 85608 SAN DIEGO, CA $92186-5608$ (858) 455-3000 